\title{
IMPLEMENTASI CASE BASED REASONING UNTUK SISTEM DIAGNOSIS PENYAKIT ANJING
}

\author{
Fransica Octaviani $\mathrm{S}^{(1)}$ \\ foctas@yahoo.com
}

\author{
Joko Purwadi $^{(2)}$ \\ jokop@ukdw.ac.id
}

\author{
Rosa Delima ${ }^{(3)}$ \\ rosa@ukdw.ac.id
}

\begin{abstract}
Abstraksi
Penalaran Berbasis Kasus / Case Based Reasoning (CBR) merupakan metode yang dipergunakan untuk membangun sebuah sistem berbasis pengetahuan. Sumber pengetahuan sistem diperoleh dengan mengumpulkan penanganan kasus-kasus oleh seorang ahli/pakar. Keuntungan dengan penerapan metode ini adalah pembangun pengetahuan tidak perlu melakukan akusisi pengetahuan secara langsung dengan seorang pakar. Pada penelitian ini penulis mengimplementasikan metode CBR untuk membantu pendiagnosisan penyakit anjing. Kasus-kasus yang dipergunakan dalam sistem diperoleh dari catatan penangan kasus diagnosa penyakit anjing dari seorang dokter hewan. Sistem akan memberikan keluaran berupa kemungkinan penyakit dan saran pengobatan yang didasarkan pada kemiripan kasus baru dengan pengetahuan yang dimiliki sistem.
\end{abstract}

Kata Kunci : Case Based Reasoning, Sistem Berbasis Pengetahuan, Knowledge Based System, penyakit anjing.

\section{Pendahuluan}

\subsection{Latar Belakang}

Sebuah sistem berbasis pengetahuan memiliki dua elemen utama yaitu basis pengetahuan/knowledge based dan kemampuan penalaran/reasoning. Basis pengetahuan merupakan elemen utama sistem karena komponen ini berisi sumber kecerdasan sistem. Banyak metode yang dapat digunakan untuk membangun sebuah basis pengetahuan diantaranya melalui interaksi langsung pembangun pengetahuan dengan ahli/pakar melalui wawancara dan observasi atau melalui catatan penangan kasus yang pernah dilakukan oleh seorang ahli. Akusisi pengetahuan melalui catatan penangan kasus yang pernah dilakukan oleh ahli memiliki banyak keuntungan diantara pengembang sistem tidak perlu berhubungan langsung dengan pakar dan proses akusisi dapat lebih singkat, sehingga memperpendek waktu pengembangan sistem. Metode yang digunakan untuk membangun sebuah sistem berbasis pengetahuan yang

${ }^{1}$ Teknik Informatika, Fakultas Teknologi Informasi,Universitas Kristen Duta Wacana

${ }^{2}$ Teknik Informatika, Fakultas Teknologi Informasi Univeristas Kristen Duta Wacana

${ }^{3}$ Teknik Informatika, Fakultas Teknologi Informasi,Universitas Kristen Duta Wacana 
pengetahuannya bersumber dari catatan kasus-kasus lampau dikenal dengan case based reasoning(CBR).

Pada penelitian ini penulis menerapkan metode CBR untuk membangun sebuah sistem yang memiliki kemampuan mendiagnosa penyakit pada anjing. Proses diagnosa penyakit pada anjing memang sebaiknya dilakukan oleh seorang pakar yang merupakan seorang dokter hewan, namun dikarenakan anjing merupakan hewan peliharaan yang umum dimiliki oleh masyarakat dan biaya untuk konsultasi ke dokter hewan juga cukup mahal maka sebagian masyarakat yang memiliki anjing biasanya melakukan pengobatan sendiri terhadapt anjing mereka yang sedang sakit. Minimnya pengetahuan yang dimiliki oleh masyarakat dapat menyebabkan penanganan yang salah terhadap anjing peliharaan mereka dan hal ini dapat berdampak fatal dan tidak jarang mengakibatkan kematian pada hewan peliharaannya. Keberadaan sistem ini diharapkan dapat membantu masyarakat dalam melakukan diagnosa awal terhadap penyakit yang diderita anjing mereka dan memberikan saran pengobatan terhadap penyakit tersebut.

\section{Landasan Teori}

\subsection{Case-Based Reasoning}

Case-Based Reasoning (CBR) adalah metode untuk menyelesaikan masalah dengan mengingat kejadian-kejadian yang sama/sejenis (similar) yang pernah terjadi di masa lalu kemudian menggunakan pengetahuan/informasi tersebut untuk menyelesaikan masalah yang baru, atau dengan kata lain menyelesaikan masalah dengan mengadaptasi solusi-solusi yang pernah digunakan di masa lalu.

Menurut Aamodt dan Plaza (1994) Case-Based Reasoning adalah suatu pendekatan untuk menyelesaikan suatu permasalahan (problem solving) berdasarkan solusi dari permasalahan sebelumnya. Case-based Reasoning ini merupakan suatu paradigma pemecahan masalah yang banyak mendapat pengakuan yang pada dasarnya berbeda dari pendekatan utama AI lainnya. Suatu masalah baru dipecahkan dengan menemukan kasus yang serupa di masa lampau, dan menggunakannya kembali pada situasi masalah yang baru. Perbedaan lain dari CBR yang tidak kalah penting adalah CBR juga merupakan suatu pendekatan ke arah incremental yaitu pembelajaran yang terus-menerus.

Dalam Case-Based Reasoning ada empat tahapan yang meliputi :

\section{a. Retrieve}

Mendapatkan/memperoleh kembali kasus yang paling menyerupai/relevan (similar) dengan kasus yang baru. Tahap retrieval ini dimulai dengan menggambarkan/ menguraikan sebagian masalah, dan diakhiri jika ditemukannya kecocokan terhadap 
masalah sebelumnya yang tingkat kecocokannya paling tinggi. Bagian ini mengacu pada segi identifikasi, kecocokan awal, pencarian dan pemilihan serta eksekusi.

\section{b. Reuse}

Memodelkan/menggunakan kembali pengetahuan dan informasi kasus lama berdasarkan bobot kemiripan yang paling relevan ke dalam kasus yang baru, sehingga menghasilkan usulan solusi dimana mungkin diperlukan suatu adaptasi dengan masalah yang baru tersebut.

\section{c. Revise}

Meninjau kembali solusi yang diusulkan kemudian mengetesnya pada kasus nyata (simulasi) dan jika diperlukan memperbaiki solusi tersebut agar cocok dengan kasus yang baru.

\section{d. Retain}

Mengintegrasikan/menyimpan kasus baru yang telah berhasil mendapatkan solusi agar dapat digunakan oleh kasus-kasus selanjutnya yang mirip dengan kasus tersebut. Tetapi Jika solusi baru tersebut gagal, maka menjelaskan kegagalannya, memperbaiki solusi yang digunakan, dan mengujinya lagi.

Empat proses masing-masing melibatkan sejumlah langkah-langkah spesifik, yang akan dijelaskan pada gambar 1 dan gambar 2 berikut ini

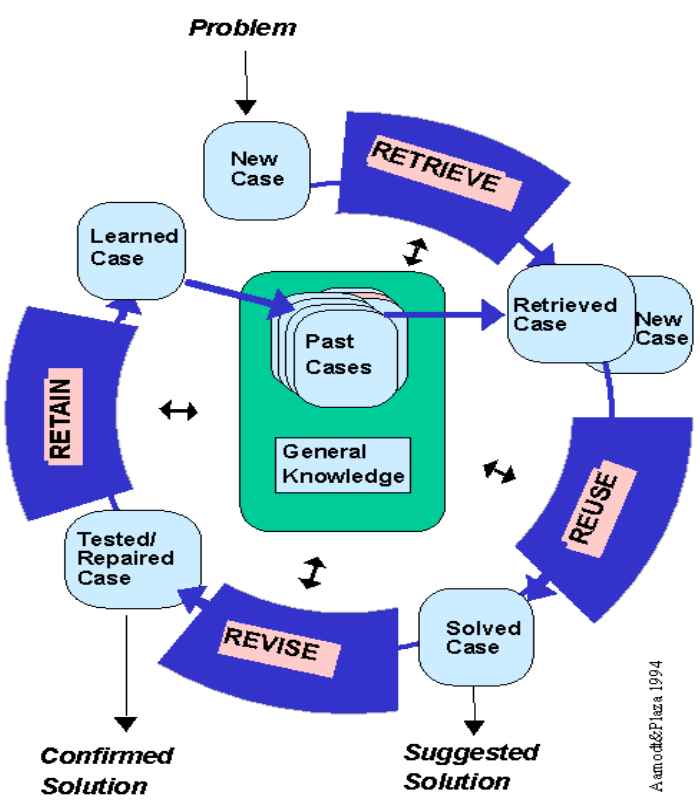

Gambar 1. Siklus Metode Case-Based Reasoning (Aamodt \& Plaza, 1994) 


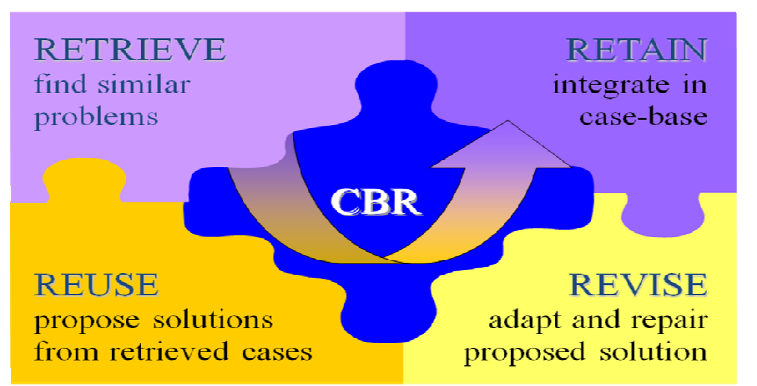

\section{Gambar 2. $\mathrm{R}^{4}$ Cycle dari Case-Based Reasoning}

Pada saat terjadi permasalahan baru, pertama-tama sistem akan melakukan proses retrieve. Proses retrieve akan melakukan dua langkah pemrosesan, yaitu pengenalan masalah dan pencarian persamaan masalah pada database.

Setelah proses retrieve selesai dilakukan, selanjutnya sistem akan melakukan proses reuse. Di dalam proses reuse, sistem akan menggunakan informasi permasalahan sebelumnya yang memiliki kesamaan untuk menyelesaikan permasalahan yang baru. Pada proses reuse akan menyalin, menyeleksi, dan melengkapi informasi yang akan digunakan.

Selanjutnya pada proses revise, informasi tersebut akan dikalkulasi, dievaluasi, dan diperbaiki kembali untuk mengatasi kesalahan-kesalahan yang terjadi pada permasalahan baru.

Pada proses terakhir, sistem akan melakukan proses retain. Proses retain akan mengindeks, mengintegrasi, dan mengekstrak solusi yang baru tersebut kedalam database. Selanjutnya, solusi baru itu akan disimpan ke dalam basis pengetahuan (knowledge-base) untuk menyelesaikan permasalahan yang akan datang. Tentunya, permasalahan yang akan diselesaikan adalah permasalahan yang memiliki kesamaan dengannya.

\subsection{Penerapan Algoritma Nearest Neighbor Retrieval Pada Metode Case-Based Reasoning}

Algoritma Nearest Neighbor Retrieval (k-nearest neighbor atau k-NN) adalah sebuah algoritma untuk melakukan klasifikas terhadap objek berdasarkan data pembelajaran yang jaraknya paling dekat dengan objek tersebut. Kasus khusus di mana klasifikasi diprediksikan berdasarkan data pembelajaran yang paling dekat (dengan kata lain, $k=1$ ) disebut algoritma nearest neighbor.

Algoritma nearest neighbor berdasarkan pada proses pembelajaran menggunakan analogi / learning by analogi. Training sampelnya dideskripsikan dalam bentuk atribut numerik n-dimensi. Tiap sampel mewakili sebuah titik pada ruang n-dimensi. Dengan cara ini, semua training sampel disimpan pada pola ruang n-dimensi. Ketika diberikan “unknown" sampel, k-nearest neighbor classifier mencari pola ruang $\mathrm{K}$ training sampel 
yang paling dekat "unknown" sampel tersebut. K training sampel ini adalah $k$ nearest neighbor dari unknown sampel. Unknown sampel ditetapkan dengan class yang paling umum diantara $k$ nearest neighborsnya. Ketika $\mathrm{k}=1$, unknown sampel ditetapkan dengan class dari training sampel yang paling dekat dengan pola ruangnya.

Algoritma nearest neighbor retrieval menyimpan semua training sampel dan tidak membangun classifier sampai sampel baru (unlabeled) perlu diklasifikasikan, sehingga algoritma nearest neighbor retrieval sering disebut dengan instance-based atau lazy learners.

Rumus untuk menghitung bobot kemiripan (similarity) dengan nearest neighbor retrieval adalah:

$$
\text { Similarity (problem,case) }=\frac{\mathrm{s}_{1} * \mathrm{w}_{1}+\mathrm{s}_{2} * \mathrm{w}_{2}+\ldots \ldots+\mathrm{s}_{\mathrm{n}} * \mathrm{w}_{\mathrm{n}}}{\mathrm{w}_{1}+\mathrm{w}_{2}+\ldots \ldots+\mathrm{w}_{\mathrm{n}}}
$$

Keterangan:

$\mathrm{S}=$ similarity (nilai kemiripan)

$\mathrm{W}=$ weight (bobot yang diberikan)

\section{Analisis Sistem}

Metode cased based reasoning merupakan metode yang menerapkan 4 tahapan proses, yaitu retrieve, reuse, revise, dan retain. Cara kerja sistem secara umum berpedoman pada basis pengetahuan yang dimiliki oleh sistem yang bersumber dari kasus-kasus yang pernah ditangani oleh seorang dokter hewan (gambar 3.) yang kemudian dihitung tingkat kemiripannya dengan kasus baru yang dimasukan pengguna (gambar 4). Berdasarkan tingkat kemiripan kasus inilah sistem akan mengeluarkan diagnosis penyakit yang diderita oleh anjing berikut saran pengobatannya.

\begin{tabular}{|l|}
\hline Kasus Lama : ID 81 \\
\hline Gejala anjing Goby: \\
Diare darah \\
Anemia \\
Dehidrasi \\
Lemas \\
Tidak mau makan \\
Diagnosa: \\
Penyakit: Coccidiosis \\
\hline Solusi: \\
Sulfadimethoxine $55 \mathrm{mg} / \mathrm{kg} \mathrm{PO}$ \\
untuk hari pertama, kemudian \\
27,5 mg/kg/hari PO selama 4 \\
hari \\
\hline
\end{tabular}

\begin{tabular}{|l|}
\hline Kasus Lama : ID 137 \\
\hline Gejala anjing Doggy: \\
Diare darah \\
Anemia \\
Dehidrasi \\
Lemas \\
Diagnosa: \\
Penyakit: Coccidiosis \\
\hline Solusi: \\
Sulfadimethoxine 55 mg/kg PO \\
untuk hari pertama, kemudian \\
27,5 mg/kg/hari PO selama 4 \\
hari \\
\hline
\end{tabular}

\begin{tabular}{|l|}
\hline Kasus Lama : ID 74 \\
\hline Gejala anjing Pokky: \\
Muntah kuning \\
Diare darah \\
Dehidrasi \\
Tidak mau makan \\
Anemia \\
Diagnosa: \\
Penyakit: Parvovirosis (CPV) \\
\hline Solusi: \\
Ciprofloxacin dosis $10-15 \mathrm{mg} / \mathrm{kg}$, \\
2x sehari. \\
Boleh ditambah vitamin B- \\
kompleks 1-5ml/kg, 2x sehari \\
Dan infus ringer laktat intravena \\
20ml/kg per hari \\
\hline
\end{tabular}

Gambar 3. Contoh kasus-kasus penyakit anjing 


\begin{tabular}{|l|}
\hline Kasus Baru $\mathbf{X}$ \\
\hline Gejala anjing $\mathbf{x}:$ \\
Diare darah \\
Dehidrasi \\
Tidak mau makan \\
Anemia \\
\hline
\end{tabular}

Gambar 4. Contoh kasus baru.

\section{a. Proses Retrieve}

Proses Retrieve merupakan proses pencarian kemiripan kasus baru dengan kasus yang lama. Pencarian kemiripan antara kasus baru dengan kasus lama dilakukan dengan cara mencocokan gejala yang diinputkan oleh pengguna dengan gejala yang ada pada basis pengetahuan. Pada proses Retrieve ini akan dilakukan pembobotan dengan menggunakan metode Nearest Neighbour Retrieval.

Pada awal proses diagnosa pengguna akan menginputkan gejala-gejala yang dialaminya. Pengguna dapat menekan tombol 'lanjut' terus-menerus sampai pertanyaan parameter gejala yang terakhir atau jika pengguna merasa bahwa gejala yang dimasukan sudah cukup maka pengguna dapat menekan tombol 'proses' untuk dapat langsung mengetahui hasil diagnosanya. Kemudian sistem akan melakukan proses pembobotan dengan melakukan pencocokan satu per satu antara gejala yang dmasukan dengan data yang ada di dalam basis pengetahuan. Proses pembobotan yang dilakukan oleh sistem ditampilkan dalam perhitungan di bawah ini.

Bobot parameter (w) :

$\begin{array}{ll}\text { Gejala Penting } & =5 \\ \text { Gejala Sedang } & =3 \\ \text { Gejala Biasa } & =1\end{array}$

$$
\text { Similarity (problem,case })=\frac{\mathrm{s}_{1} * \mathrm{w}_{1}+\mathrm{s}_{2} * \mathrm{w}_{2}+\ldots \ldots+\mathrm{s}_{\mathrm{n}} * \mathrm{w}_{\mathrm{n}}}{\mathrm{w}_{1}+\mathrm{w}_{2}+\ldots \ldots+\mathrm{w}_{\mathrm{n}}}
$$

Keterangan:

$\mathrm{S}=$ similarity (nilai kemiripan) yaitu 1 (sama) dan 0 (beda)

$\mathrm{W}=$ weight (bobot yang diberikan)

\section{Perhitungan kasus 1 :}

Bobot gejala penyakit Coccidiosis :

Diare darah $\quad=5$

Anemia $\quad=5$


Dehidrasi $\quad=3$

Lemas $\quad=1$

Tidak mau makan $\quad=1$

\begin{tabular}{|c|c|c|}
\hline Kasus Baru X & & Kasus Lama : ID 81 \\
\hline \multirow{4}{*}{$\begin{array}{l}\text { Gejala anjing } \mathbf{x} \text { : } \\
\text { Diare darah } \\
\text { Dehidrasi } \\
\text { Tidak mau makan } \\
\text { Anemia }\end{array}$} & 5 & \multirow{4}{*}{$\begin{array}{l}\text { Gejala anjing Goby: } \\
\text { Diare darah } \\
\text { Anemia } \\
\text { Dehidrasi } \\
\text { Lemas } \\
\text { Tidak mau makan }\end{array}$} \\
\hline & 5 & \\
\hline & 3 & \\
\hline & 1 & \\
\hline
\end{tabular}

Similarity $(X, 81)=\frac{[(1 * 5)+(1 * 5)+(1 * 3)+(0 * 1)+(1 * 1)]}{5+5+3+1+1}$

$=0,9333$

Perhitungan kasus 2 :

\begin{tabular}{|c|c|c|}
\hline Kasus Baru X & & Kasus Lama : ID 137 \\
\hline \multirow{3}{*}{$\begin{array}{l}\text { Gejala anjing } \mathbf{x}: \\
\text { Diare darah } \\
\text { Dehidrasi } \\
\text { Tidak mau makan } \\
\text { Anemia }\end{array}$} & 5 & \multirow{3}{*}{$\begin{array}{l}\text { Gejala anjing Doggy: } \\
\text { Diare darah } \\
\text { Anemia } \\
\text { Dehidrasi } \\
\text { Lemas }\end{array}$} \\
\hline & 5 & \\
\hline & 3 & \\
\hline
\end{tabular}

Similarity $(X, 137)=\frac{[(1 * 5)+(1 * 5)+(1 * 3)+(0 * 1)]}{5+5+3+1}$

$$
=0,9286
$$

Bobot gejala penyakit Parvovirosis (CPV)

$\begin{array}{ll}\text { Muntah kuning } & =5 \\ \text { Diare darah } & =5 \\ \text { Dehidrasi } & =3 \\ \text { Anemia } & =3 \\ \text { Tidak mau makan } & =1\end{array}$

Perhitungan kasus 3 :

\begin{tabular}{|c|c|c|}
\hline Kasus Baru X & & Kasus Lama : ID 74 \\
\hline \multirow{4}{*}{$\begin{array}{l}\text { Gejala anjing } \mathbf{x} \text { : } \\
\text { Diare darah } \\
\text { Dehidrasi } \\
\text { Tidak mau makan } \\
\text { Anemia }\end{array}$} & 5 & \multirow{4}{*}{$\begin{array}{l}\text { Gejala anjing Pokky: } \\
\text { Muntah kuning } \\
\text { Diare darah } \\
\text { Dehidrasi } \\
\text { Tidak mau makan } \\
\text { Anemia }\end{array}$} \\
\hline & 3 & \\
\hline & 1 & \\
\hline & 3 & \\
\hline
\end{tabular}


Similarity $(X, 74)=\frac{[(0 * 5)+(1 * 5)+(1 * 3)+(1 * 1)+(1 * 3)]}{5+5+3+3+1}$

$$
=0,7058
$$

\section{b. Proses Reuse}

Dari perhitungan diatas kasus yang memiliki bobot kemiripan paling rendah adalah kasus ID 74 yaitu sebesar 0,7058. Kasus ID 81 dan ID 137 menghasilkan bobot kemiripan yang hampir sama tinggi yaitu 0,9333 dan 0,9286, hanya selisih sedikit saja yaitu sebesar 0,0047 .

Pada proses reuse, solusi yang diberikan adalah solusi dengan bobot kemiripan kasus lama dengan kasus baru yang paling tinggi, dalam contoh kasus ini adalah kasus ID 81 yaitu anjing Goby. Hasil perhitungan dengan bobot menunjukkan tingkat kepercayaan lebih dari 90\%, jadi solusi kasus ID 81 lah yang direkomendasikan kepada pengguna yaitu Sulfadimethoxine $55 \mathrm{mg} / \mathrm{kg}$ PO untuk hari pertama, kemudian $27,5 \mathrm{mg} / \mathrm{kg} / \mathrm{hari}$ PO selama 4 hari.

Pada gambar 5 dapat dilihat bahwa hasil perhitungan manual dan program cocok, yaitu menghasilkan output penyakit Coccidiosis beserta solusi pengobatannya.

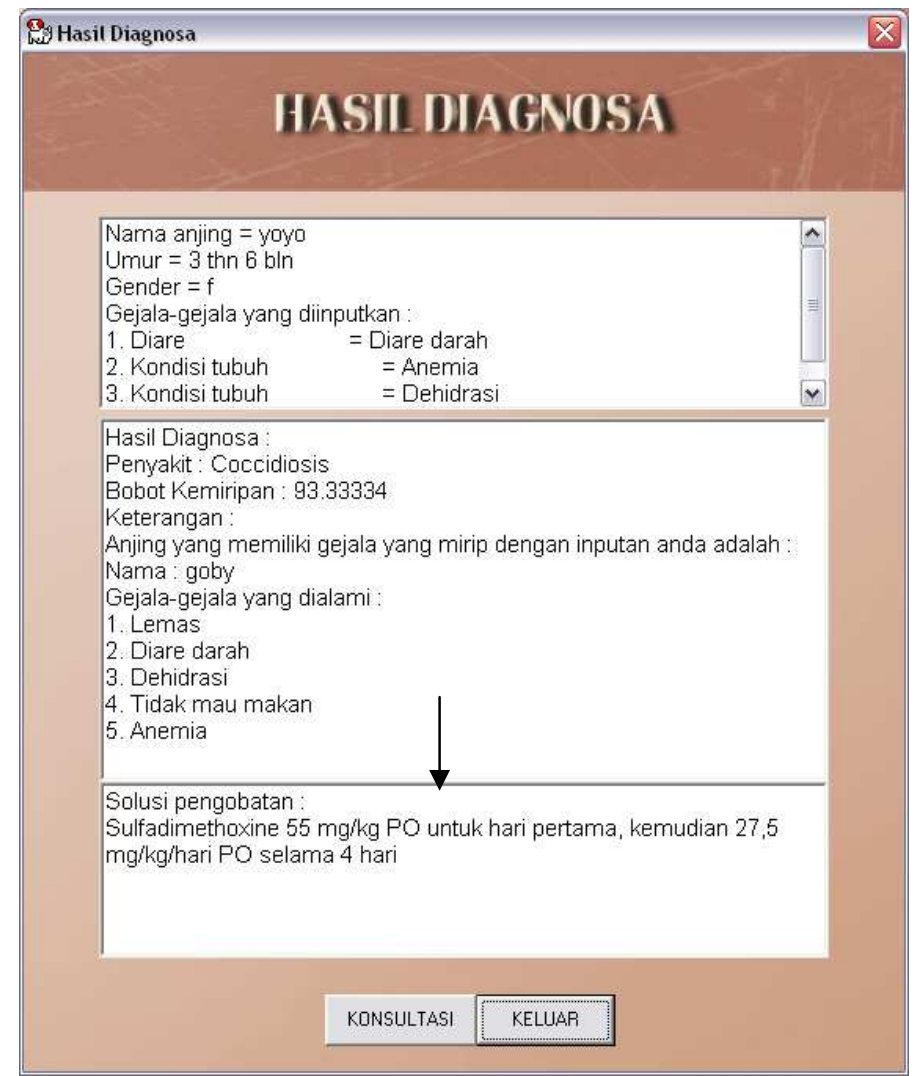

Gambar 5. Gambar Penelusuran Penyakit Anjing 


\section{c. Proses Revise}

Proses revise adalah proses peninjauan kembali kasus dan solusi yang diberikan jika pada proses retrieve sistem tidak dapat memberikan hasil diagnosa yang tepat. Pada contoh ini kasus anjing Goby sudah menghasilkan solusi dengan tingkat kepercayaan diatas 90\%, jadi solusi yang dihasilkan dapat langsung diberikan.

Tetapi jika ternyata setelah dilakukan proses perhitungan dan tidak ada kasus yang mirip dengan kasus baru tersebut maka dilakukan proses revise. Informasi berupa masukan gejala pada kasus baru yang tidak ditemukan kemiripannya dengan basis pengetahuan (rule) tersebut akan ditampung pada suatu tabel khusus (tabel revise) yang selanjutnya akan dievaluasi dan diperbaiki kembali oleh pakar untuk menemukan solusi yang tepat.

\section{d. Proses Retain}

Setelah proses revise selesai dan sudah ditemukan solusi yang benar-benar tepat barulah pakar mulai menambah aturan dengan memasukkan data kasus baru yang sudah ditemukan solusinya tersebut ke dalam basis pengetahuan yang nantinya dapat digunakan untuk kasus berikutnya yang memiliki permasalahan yang sama. Proses inilah yang disebut dengan proses retain.

\section{Kesimpulan}

Berdasarkan hasil implementasi dan analisis sistem maka dapat disimpulkan :

1) Berdasarkan uji tes beta yang dilakukan, sistem pakar dapat melakukan diagnosis penyakit anjing dengan cukup baik.

2) Fasilitas modifikasi aturan (rule) yang diberikan memberikan kemudahan bagi pakar untuk mengubah aturan sehingga sistem ini dapat selalu diperbaharui dan dikembangkan sesuai kebutuhan.

\section{Daftar Pustaka}

Aamodt, A \& Plaza, E, 1994, Case Based Reasoning: Foundation Issues Methodological Variations, and System Approaches, AI Communication Vol 7 Nr, 1 March 1994, pp 39-59.

Subronto, 2006. Penyakit Infeksi Parasit dan Mikroba pada Anjing dan Kucing. Yogyakarta: GADJAH MADA UNIVERSITY PRESS.

Turban, E., Aronson, J.E., \& Liang, T.P., 2005, Decision Support System and Intelligent System, New Jersey: Pearson Education, Inc.

Watson, I., 1997, Applying Case Based Reasoning: Techniques for Enterprise Systems. San Fransisco: Morgan Kaufmann Publisher, Inc. 